\title{
Comportamento de empresários e consumidores de academias de ginástica na adaptação de atividades físicas durante a pandemia de COVID-19
}

\author{
Fitness center entrepreneurs' and consumers' behavior in adapting for physical activities during
} the COVID-19 pandemic

Comportamiento de los empresarios y consumidores de gimnasios en la adaptación de las actividades físicas durante la pandemia de COVID-19

\section{Resumo}

A pandemia de Corona Virus Disease 2019 (COVID-19) tem causado momentos de incertezas, neutralizado atividades econômicas e adaptado práticas de rotina. Contudo, nem todos os segmentos empresariais estão preparados para responder rapidamente às eventualidades, sobretudo as Micro e Pequenas Empresas (MPE's). O elemento central deste artigo foi identificar quais os tipos de comportamento de empresários e consumidores de micro e pequenas academias de ginástica na adaptação das práticas de atividades físicas em tempos de pandemia. O contexto das academias foi escolhido por ser um dos setores da economia mais impactados financeiramente em virtude do isolamento social, proibição de aglomeração de pessoas e da dependência do espaço físico para exercer atividades. Por meio de uma metodologia baseada em netnografia, durante o inverno do ano de 2020 foram coletados e analisados dados de perfis da rede social Instagram de 42 academias, sete personal trainers e 28 consumidores, além de 13 hashstags. Como resultado, foram encontrados quatro tipos de comportamentos de empresários e consumidores, a saber: adaptador, resiliente, desistente e negador. Acredita-se que este artigo irá contribuir no entendimento das mudanças e adaptações de MPE's em momentos de incertezas. Sob a perspectiva dos empresários de academias de ginástica e seus consumidores, as conclusões provenientes da pesquisa destacam que a pandemia foi um meio para o setor aperfeiçoar o modo de ofertar o serviço por intermédio da adição de novos hábitos e necessidades de consumo que poderão apontar novas rotinas e tendências pós-pandemia.

Palavras-chave: Momentos de incertezas; Ruptura de rotinas; Micro e pequena empresa; Academias de ginástica; Comportamento de empresários e consumidores.

\begin{abstract}
The Corona Virus Disease 2019 (COVID-19) pandemic has caused moments of uncertainty, neutralized economic activities, and adapted routine practices. However, some business segments are not prepared to respond quickly to eventualities, especially Micro and Small Enterprises (MSE's). This article's central element was to identify the types of behavior of entrepreneurs and consumers of micro and small gyms in adapting physical activity practices in times of a pandemic. We choose the fitness context because it is one of the sectors of the economy that was the most financially impacted due to social isolation, prohibition of agglomeration of people, and dependence on physical space to carry out activities. Through a methodology based on netnography, during the winter of 2020, data from the profiles of the Instagram social network of 42 gyms, 7 personal trainers, and 28 consumers were collected and analyzed, in addition to 13 hashtags. As a result, we found four types of behaviors of entrepreneurs and consumers: adaptor, resilient, quitter, and denier. We believe that this article will contribute to the understanding of MPE's changes and adaptations in moments of uncertainty. From the perspective of fitness center entrepreneurs and their consumers, the findings from the survey highlight that the pandemic was a means for the sector to improve the way it
\end{abstract}


offered the service through the addition of new habits and consumption needs that could point to new post-pandemic routines and trends.

Keywords: Moments of uncertainty; Routine disruption; Micro and small enterprise; Gym; Behavior of entrepreneurs and consumers.

\begin{abstract}
Resumen
La pandemia del Corona Virus Disease 2019 (COVID-19) ha provocado momentos de incertidumbre, actividades económicas neutralizadas y prácticas rutinarias adaptadas. Sin embargo, no todos los segmentos de negocio están preparados para responder rápidamente ante eventualidades, especialmente las Micro y Pequeñas Empresas (MPE’s). El elemento central de este artículo fue identificar los tipos de comportamiento de los empresarios y consumidores de micro y pequeños gimnasios en la adaptación de las prácticas de actividad física en tiempos de pandemia. Se eligió el contexto de las academias por ser uno de los sectores de la economía más impactados económicamente debido al aislamiento social, prohibición de aglomeración de personas y dependencia del espacio físico para la realización de actividades. Através de una metodología basada en netnografía, durante el invierno de 2020 se recopilaron y analizaron datos de los perfiles de la red social Instagram de 42 gimnasios, 7 entrenadores personales y 28 consumidores, además de 13 hashtags. Como resultado, se encontraron cuatro tipos de comportamientos de empresarios y consumidores, a saber: adaptador, resiliente, renunciador y negador. Se cree que este artículo contribuirá a la comprensión de los cambios y adaptaciones de los MPE en momentos de incertidumbre. Desde la perspectiva de los empresarios de gimnasios y sus consumidores, los resultados de la encuesta destacan que la pandemia fue una forma de que el sector mejorara la forma en que ofrecía el servicio mediante la incorporación de nuevos hábitos y necesidades de consumo que podrían apuntar a nuevos rutinas y tendências después de la pandemia.

Palabras clave: Momentos de incertidumbre; Interrupción de la rutina; Micro y pequeña empresa; Gimnasios; Comportamiento de empresarios y consumidores.
\end{abstract}

\title{
1. Introdução
}

A pandemia de Corona Virus Disease 2019 (COVID-19) tem ocasionado situações de incertezas nos mercados globais, neutralizado atividades econômicas e adaptado práticas de rotina. Tanto as organizações como seus respectivos consumidores tiveram que rapidamente se adaptar a um momento repleto de dúvidas, ambiguidades e imprecisões (Aquino et al., 2020). A singularidade e unicidade da pandemia provocaram desdobramentos rápidos e ações como distanciamento social, isolamento, quarentena, contenção na indústria, fechamento temporário no comércio e serviço, entre outras medidas de restrição (Bezerra et al., 2020). E tais determinações suscitaram impactos expressivos nos hábitos das pessoas e nas economias dos empreendimentos.

Mas, nem todos os segmentos empresariais estavam preparados para responder rapidamente às eventualidades, em particular as Micro e Pequenas Empresas (MPE's). Em pesquisa realizada no mês de abril de 2020, início da pandemia, o Serviço Brasileiro de Apoio às Micro e Pequenas Empresas (SEBRAE, 2020) constatou que o faturamento dos pequenos empresários teve queda de $69 \%$ em referência a uma semana normal de meses anteriores, o que revela que tais negócios são extremamente sensíveis à crises globais. Por dispor de administração centralizada no gestor/proprietário, equipe de funcionários pequena e poucos recursos para responderem à momentos de incertezas como uma pandemia, os empresários precisam agir com celeridade na gestão da MPE acerca da concepção de estratégias que controlam a direção, a organização e o ambiente no qual a empresa está inserida (Almeida et al., 2021).

Em setores específicos como o mercado fitness, sobretudo as academias de ginástica, o consumo despencou no começo da pandemia e a recuperação econômica está sendo lenta (Bisneto \& Simão, 2020). Por efeito da aglomeração de pessoas exaustas e ofegantes em um ambiente fechado e de alto compartilhamento de aparelhos de ginástica, as academias foram apontadas por muitos governos locais como uma das atividades econômicas mais vulneráveis para a propagação da COVID-19 (Camilo et al., 2020). Ainda por cima, a ruptura de rotinas durante a pandemia aumentou o comportamento sedentário da população e, por consequência, acarretou a obesidade, um dos grandes fatores de risco para o agravamento da doença (Alecrim, 2020). 
Jankowska (2021) e Oliveira et al. (2020) revelam que o autocuidado deve estar inserido na busca de maior qualidade de vida, independentemente da situação na qual esses indivíduos estão inseridos, pois é preciso estimular a saúde por intermédio das atividades físicas e elaborar planos para reverter os indicadores de sedentarismo. Apesar das incertezas na economia afetarem diretamente a inovação nas academias de ginástica, o segmento se adaptou, entre outras práticas, ao uso de tecnologia - como a rede social de entretenimento - para agregar valor e alcançar um maior número de consumidores por intermédio de aulas ofertadas pela Internet (Rodrigues et al., 2020).

A partir desse entendimento, este artigo busca responder à seguinte situação-problema: Como os momentos de incertezas e ruptura de rotinas tem impactado os empresários e consumidores do mercado fitness? O objetivo é identificar quais os tipos de comportamento de empresários e consumidores de micro e pequenas academias de ginástica na adaptação das práticas de atividades físicas em tempos de pandemia. Para isso, foi utilizada uma metodologia baseada em netnografia (Kozinets, 2020). A localidade escolhida para o estudo foi a microrregião do Médio Piracicaba, região Central do estado de Minas Gerais, que possui 42 academias de ginástica registradas no Conselho Federal de Educação Física (CONFEF, 2020) e com perfis ativos no Instagram. As organizações estão distribuídas em 12 municípios da microrregião.

O encadeamento das academias de ginástica com os cuidados da saúde e bem-estar é importante por se tratar de uma questão polêmica ao confrontar economia e saúde pública. Por ser um dos setores mais impactados em virtude da aglomeração de pessoas e da grande dependência do espaço físico para funcionar, este estudo contribui no entendimento das mudanças e adaptações das academias de ginástica sob a perspectiva dos empresários e seus consumidores e o contato com a rede social mediante os quatro tipos de comportamentos resultados da pesquisa: adaptador, resiliente, desistente e negador. Para responder o questionamento feito, a próxima seção deste artigo exibe uma breve fundamentação teórica sobre o tema. Em seguida, apresenta-se a metodologia, os resultados e a discussão. Por fim, são expostas as considerações finais da pesquisa e as referências utilizadas.

\section{Fundamentação Teórica}

De acordo com o Ministério da Saúde, a COVID-19 é uma doença que exibe um quadro clínico que pode variar de infecções assintomáticas a quadros respiratórios graves. Sua transmissão acontece de uma pessoa doente para outra por contato próximo por meio do toque do aperto de mão, gotículas de saliva, espirro, tosses, aerossóis (partículas ainda menores que as gotículas) e, às vezes, objetos contaminados pelo vírus. As formas mais eficazes para conter a disseminação da doença são o distanciamento social, isolamento e quarentena, que evitam aglomerações de pessoas (Brasil, 2022).

Essas medidas para conter a dissipação da doença impactam diretamente na economia do país, visto que empresas de diversos portes e setores são forçadas a fechar suas portas e/ou funcionar de forma remota. O estudo de Murphy, Naert e Strong (2020) ressalta que em ambiente de incertezas como o causado pela pandemia de coronavírus, o comportamento do consumidor, os hábitos de consumo e a comunicação por parte de empresários e seus respectivos consumidores mudam consideravelmente. Na visão dos autores, para manter as atividades, o ambiente exige das organizações uma resposta rápida frente aos acontecimentos, além da reconfiguração, redirecionamento, transformação, formatação e integração nas diversas atividades que compõem a construção de estratégias. A seguir, será exibida a relação entre os empresários e consumidores das micro e pequenas academias de ginástica com a pandemia de COVID-19.

\subsection{Empresários de micro e pequenas academias de ginástica em tempos de pandemia}

Conduzir uma empresa não é uma função simples. Seja qual for o tamanho do estabelecimento, qualquer gestor poderá enfrentar dificuldades que interferem na qualidade da prestação de serviço ao consumidor (Almeida, 2020). Além do mais, nem todos os segmentos empresariais estão preparados para responderem rápido as eventualidades, em particular as 
MPE’s, que figuram uma estrutura organizacional com poucos níveis hierárquicos e a gestão centralizada no gestor/proprietário (Martins et al., 2017).

Por possuírem equipes de funcionários pequenas e estruturas escassas para enfrentar os momentos de incertezas, os empresários das MPE's precisam gerir os gastos de modo eficiente no intuito de equilibrarem as finanças e manterem o desempenho regular, pelo menos, perante a concorrência. Isso porque o mercado no qual diferentes tamanhos de empresas estão inseridos é fortemente competitivo e um empresário bem preparado é essencial para a sobrevivência e prosperidade da organização (Almeida, 2019, 2020).

Gerir uma MPE requer uma visão sistêmica e compreensão das especificidades na criação de estratégias que a controlam (Almeida et al., 2021). Terence (2008) trata da temática pelas vias dirigente, organização e ambiente. A Figura 1 descreve as especificidades e suas três dimensões por um triângulo. Os vértices retratam as dimensões dirigente, organização e ambiente, e o centro, a estratégia. A tipologia demonstra a perspectiva de se caracterizar a MPE a partir das três dimensões inter-relacionadas que a controlam na elaboração de estratégias. O propósito da gestão de MPE é de entender as especificidades da pequena empresa e a técnica de criação de estratégias que é distinta das grandes empresas em momentos de incertezas.

Figura 1 - Dimensões de especificidades de gestão de MPE.

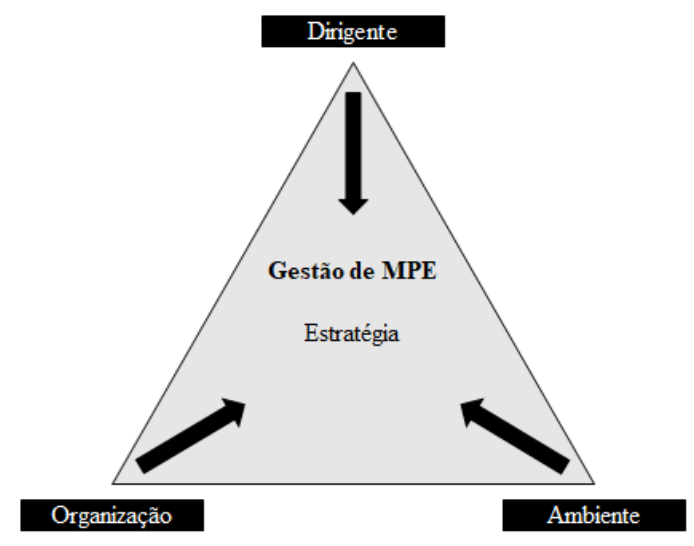

Fonte: Adaptado de Terence (2008).

Nas especificidades do dirigente, destaca-se o papel dominante de uma só pessoa: o gestor/proprietário. O gestor trabalha próximo aos seus funcionários, tem o papel estrategista e um perfil individualista. Nas especificidades da organização, as MPE’s são caracterizadas por terem menor controle do ambiente externo e possuírem estratégia intuitiva e pouco formalizada. E nas especificidades do ambiente, isto é, relativas ao contexto em que a pequena empresa está inserida, as tomadas de decisão são feitas, na maioria das vezes, em curto prazo (Martins et al., 2017).

As MPE's participam de forma efetiva no contexto socioeconômico brasileiro. No ano de 2018, segundo o SEBRAE e o Departamento Intersindical de Estatística e Estudos Socioeconômicos (DIEESE), as empresas de pequeno porte representavam cerca de 7,1 milhões dos estabelecimentos e eram responsáveis por 17,8 milhões de empregos formais privados do país (SEBRAE \& DIEESE, 2020). Já o mercado fitness, foco deste estudo, no ano de 2019 movimentou 2,1 bilhões de dólares no Brasil, sendo o segundo mercado mundial em número de academias de ginástica e o primeiro da América Latina, com 29.525 unidades. Em termos de número de membros, o país ocupava o quarto lugar no ranking mundial, com aproximadamente 10,3 milhões de clientes, conforme o relatório global do International Health, Racquet \& Sportsclub Association (IHRSA, 2020). 
As academias de ginástica têm sido fortemente afetadas pela crise da COVID-19, pois priorizam o seu funcionamento na dependência de um ambiente físico. Vale frisar que os problemas envolventes nos momentos de incertezas afetam de diferentes maneiras as pequenas e grandes empresas do mercado fitness. Por esse motivo, as medidas para conter a disseminação da doença fizeram com que o meio digital ganhasse força no setor. Embora as restrições de distanciamento social possam incluir o fechamento de academias e clubes esportivos, a atividade física precisa ser promovida e incentivada. Dessa maneira, foi preciso que as MPE's do setor se reinventassem e agregassem valor na decisão do consumidor. E as novas tecnologias têm contribuído para atender as necessidades dos clientes, o que permite tais empresas inovarem, atuarem em novos modelos de negócios e atingirem maiores amplitudes (Araújo Júnior et al., 2020; Carvalho et al., 2020; Raiol, 2020; Rodríguez-Cañamero et al., 2018).

Bodlaj e Cater (2019) ressaltam que tanto a incerteza no mercado quanto a tecnológica aumentam a importância percebida da inovação, mas apenas a incerteza do mercado afeta diretamente as empresas de pequeno porte. Assim também, Lima e Silva (2019) apontam que, de modo geral, as MPE's consideram a inovação como uma importante ferramenta de crescimento empresarial. Porém, tal prática vem sendo aplicada de modo informal, proveniente da falta de recursos financeiros para investir.

\subsection{Consumidores de micro e pequenas academias de ginástica em tempos de pandemia}

Em momentos de incertezas como o da pandemia de COVID-19, as micro e pequenas academias de ginástica sustentam seus negócios por meio da melhoria de seus produtos, serviços e processos, na qualificação da equipe de funcionários, no planejamento de suas práticas do cotidiano e na orientação do mercado no que se refere aos impactos e tendências em decorrência da crise. Migrar as aulas e acompanhamentos para as redes sociais de entretenimento e incentivar a prática de atividade física e redução do comportamento sedentário são algumas condutas para os empresários contornarem as incertezas e manterem e/ou atraírem novos consumidores (Guimarães et al., 2020).

Vale ressaltar que momentos de incertezas sempre existiram na sociedade, como aquele estudado por Phipps e Ozanne (2017) para entender como as pessoas se sentem com relação à segurança quando suas rotinas são interrompidas. Para os autores, a rotina é parte onipresente da vida e a interrupção dela impacta diretamente as diversas práticas do cotidiano. O zelo com a saúde está vigente ao longo da existência e é garantido pelas diferentes práticas de cuidado realizadas. A questão é se essas atividades são mantidas em situações extremas em que todos param abruptamente, como em uma pandemia.

Os consumidores se envolvem em atividades rotineiras na maior parte do tempo e alguns padrões de consumo refletem o que geralmente são rotinas e hábitos imperceptíveis, como por exemplo, escovar os dentes, tomar banho, cozinhar, se vestir, dirigir, fazer compras nas mesmas lojas físicas/virtuais e comprar praticamente os mesmos produtos e fazer exercícios físicos. Muitas dessas rotinas são ou se tornaram parte da vida das pessoas sem até mesmo que elas percebam, até que elas sejam, de alguma forma, interrompidas (Shove, 2003).

A desconstrução de rotinas e objetos materiais, como a análise de Magaudda (2011), é uma questão relevante, principalmente quando se considera as mudanças em andamento no consumo de serviços. Já na perspectiva dos empresários, os eventos determinantes na criação de estratégias em MPE's ajudam a compreender o comportamento dos gestores/proprietários frente aos momentos de incertezas, como no artigo de Terence, Escrivão Filho e Perussi Filho (2012). E mais recentemente, a pesquisa de Lang et al. (2021) apoia, por meio de definições e tipologias, o estudo das implicações da pandemia de COVID-19 para empresários e consumidores de serviços.

Quanto a prática de atividades físicas, alguns estudos já trazem como a pandemia de COVID-19 mudou a vida das pessoas (Aquino et al., 2020; Araújo Júnior et al., 2020; Carvalho et al., 2020; Feter et al., 2021; Guimarães et al., 2020; Jankowska, 2021; Raiol, 2020; Sá et al., 2020). No entanto, é importante pesquisar como tanto os empresários quanto os 
consumidores de micro e pequenas academias de ginástica reagem a essa mudança repentina e como se adaptam às tecnologias, como por exemplo, a rede social de entretenimento. Assim, este artigo busca entender como esses atores adaptaram suas práticas de atividades físicas em tempos de pandemia. A seguir, será apresentado os procedimentos metodológicos para atingir o objetivo proposto.

\section{Metodologia}

A pesquisa foi conduzida com base na netnografia, que pode ser interpretada como uma forma especializada de etnografia fundamentada na comunicação mediada por computador, como fonte de dados para compreender e representar etnograficamente um fenômeno cultural na Internet. O método possibilita uma maior familiaridade com o fenômeno pesquisado, o que permite o entendimento de quais atores são mais relevantes para a investigação (Kozinets, 2020).

Para isso, com intensa ação do primeiro autor deste artigo, em um primeiro instante foi feito o acompanhamento constante nos perfis do Instagram de micro e pequenas academias de ginástica, personal trainers e consumidores com atuação voltada aos temas do mercado fitness. A localidade escolhida para o estudo foi a microrregião do Médio Piracicaba, região Central do estado de Minas Gerais, onde a instituição de ensino, pesquisa e extensão dos autores está inserida.

$\mathrm{Na}$ sequência, foi criado um perfil específico na referida rede social com a intenção de seguir contas e hashtags temáticas relacionados às atividades de bem-estar e exercícios físicos, a saber: 77 contas (42 perfis de academias de ginástica ativas na rede social e registradas no CONFEF; sete perfis de personal trainers; e 28 perfis de consumidores) e 13 hashstags (\#Academia; \#AcademiaEmCasa; \#AcademiaOnline; \#DicasDeTreino; \#Gym; \#HomeFitness; \#HomeGym; \#HomeWorkout; \#QuarentenaFitness; \#Quarentreino; \#TreineEmCasa; \#TreinoCriativo; e \#TreinoOnline).

Durante a observação e iteração, o número de perfis seguidos variou. Isso se deve a necessidade de observar a saturação teórica dos dados e a redundância empírica que, de acordo com Belk et al. (2013), é a forma de determinar o tempo de finalização da coleta de dados. Portanto, ao atingir esse nível de saturação, a coleta de dados foi encerrada. Tal coleta foi feita diariamente em cada perfil da rede social, além do convívio e das anotações de campo do primeiro autor.

Os atores foram seguidos durante os meses de junho, julho e agosto de 2020, momento da primeira onda da pandemia com distanciamento social, isolamento, quarentena, fechamento temporário no comércio e serviço, entre outras medidas de restrição. Foram recolhidos 1.397 posts ( $312 \mathrm{em}$ junho, $548 \mathrm{em}$ julho e $537 \mathrm{em}$ agosto) e feita aproximadamente 100 horas de observação e iteração on-line. A análise contínua durante o período possibilitou fazer comparações entre os instantes de fechamento/abertura parcial das micro e pequenas academias de ginásticas e observar as tendências no mercado fitness.

Os dados foram armazenados em forma imagem (fotos, vídeos e conteúdos publicados) e textos. O tratamento dos textos seguiu as recomendações de Rose (2016) e foram usados, em princípio, para apoiar a discussão dos resultados, não como dado principal da pesquisa. Assim, no decorrer do período de imersão no campo, os pesquisadores coletaram dados secundários em revistas e jornais com o intuito de entender a situação do mercado fitness e as mudanças ao longo do tempo do fenômeno social de atividades de bem-estar relacionadas aos exercícios físicos, bem como para avaliar a importância do tema enquanto construção social (Golder, 2000). Os procedimentos metodológicos realizados nesta investigação estão representados na Figura 2, que proporciona um melhor entendimento da metodologia. A próxima seção irá expor e discutir a tipologia de empresários e consumidores de micro e pequenas academias de ginásticas. 


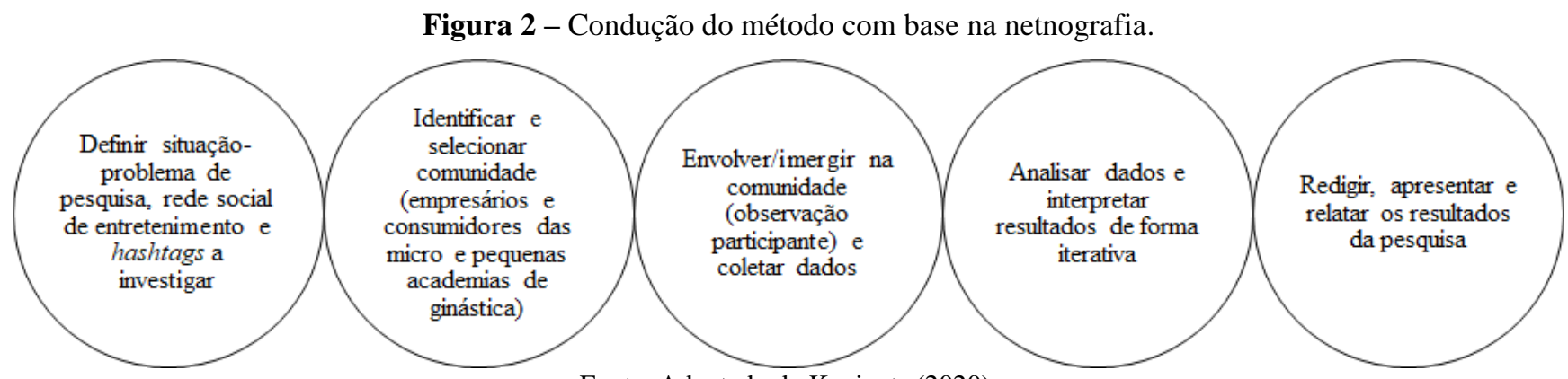

Fonte: Adaptado de Kozinets (2020).

\section{Resultados}

Com base na netnografia, a análise dos dados e a interpretação dos resultados foram feitas de modo iterativo. Em virtude da pandemia de COVID-19, durante meses empresários e consumidores do mercado fitness interromperam as rotinas e criaram novos hábitos para ajustar o ensino e a prática das atividades físicas. Por consequência do isolamento social e das restrições para sair de casa, o que antes era feito em academias de ginástica e parques ao ar livre passou por adaptações. Assim, as rotinas dos empresários e consumidores de micro e pequenas academias de ginásticas foram adequadas e o quintal de casa ou a sala de estar - com o auxílio da tecnologia se transformou em um espaço para a realização das atividades físicas.

Apesar disso, tanto empresários quanto consumidores se comportaram de formas distintas durante o período da pesquisa, o que foi aqui estruturado como uma tipologia. Os tipos de comportamento dos micro e pequenos empresários de academias de ginástica foram fundamentados nos modos de formação de estratégias de Terence, Escrivão Filho e Perussi Filho (2012) e estão associados à forma como o gestor/proprietário se portou perante a pressão dos governos locais em manter as empresas fechadas durante as restrições e não perder consumidores; respeito às regras sanitárias; e adaptação do seu negócio para manter parte do faturamento. Por sua vez, o comportamento dos consumidores de academias foi apoiado no circuito da prática de consumo de Magaudda (2011) e diz respeito a maneira pela "qual", "como", "onde" e "se" o consumidor decidiu adaptar e praticar exercícios físicos durante a primeira onda da pandemia de COVID-19. Foram encontrados quatro tipos de comportamentos de empresários e consumidores, a saber: adaptador, resiliente, desistente e negador.

Para melhor entender a construção da tipologia do comportamento de empresários e consumidores de academias de ginástica na adaptação de atividades físicas durante a pandemia de COVID-19, foram desenvolvidos quadros (ver Quadros 1 e 2 nas seções a seguir) para apontar o tipo de empresário ou consumidor; a característica, o foco e o perfil de cada um deles; o objeto que foi utilizado na adaptação das atividades físicas; o significado de cada objeto; e a ação praticada por cada tipo de empresário ou consumidor diante dos momentos de incertezas e ruptura de rotinas.

\subsection{Comportamento de empresários de micro e pequenas academias de ginástica}

Os empresários "adaptadores" enxergaram uma oportunidade na pandemia e adequaram, ajustaram e moldaram a forma de ensinar e orientar as atividades físicas por meio de aulas e consultorias on-line (ver Figura 3a). Por terem um perfil adaptativo, a criação de estratégias para contornar a crise focou em um processo incremental de análise do ambiente e a ação foi tomada em conjunto com os funcionários, o que implicou uma adaptação contínua da academia ao seu ambiente e às condições internas e externas. A rede social de entretenimento Instagram foi utilizada como suporte para exibir as aulas (fotos, lives e reels) e, mediante ao aluguel de equipamentos de ginástica, foi possível criar um novo negócio. Vários desses empresários investiram em estudos e cursos para ampliar a oferta de serviço.

Os "resilientes" são empresários com perfis firmes e flexíveis (ver Figura 3b). No início da pandemia até desanimaram, mas para manter a MPE aberta e não fechar as portas, formularam estratégias e implantaram para poucos 
consumidores algumas aulas on-line por meio de vídeo-chamadas ao vivo (lives) e/ou visitas às residências para ensinar e auxiliar as atividades físicas. Por deterem um perfil racional, a criação de estratégias destacou a formulação e estabelecimento de planos que, somente depois de algumas semanas do início da pandemia, foram implantados e avaliados junto aos colaboradores das academias. Esses empresários saíram da organização física (academia de ginástica) e foram até aos consumidores oferecerem os serviços.

Com um perfil pouco emergente, os empresários "desistentes" abdicaram, abandonaram e cessaram os planos de manter o negócio aberto (ver Figura 3c). Alguns deles declararam falência e outros fecharam as portas e aguardaram as autoridades locais liberarem a abertura das academias de ginástica. Não enxergaram oportunidades em nenhuma das dimensões de especificidades de gestão de MPE (ver Figura 1) e focaram de forma inadequada a criação de estratégias.

Os empresários "negadores" miraram um foco inadequado na dimensão dirigente (ver Figura 3d). Com perfil pouco empreendedor, foram teimosos, insistentes e rejeitaram os decretos das autoridades locais para a limitação do funcionamento das academias. Além de continuarem com os estabelecimentos abertos durante a pandemia, não utilizaram de forma adequada as recomendações sanitárias, como por exemplo, o uso de máscara, álcool em gel 70\% e higienização dos equipamentos de ginástica. As estratégias criadas foram centradas no gestor/proprietário (individualista). O Quadro 1 sintetiza e relaciona os tipos de empresários e suas características, focos e perfis com os objetos, significados e ações.

Quadro 1 - Tipos de empresários.

\begin{tabular}{|c|c|c|c|c|}
\hline Tipo & $\begin{array}{c}\text { Característica, foco e } \\
\text { perfil }\end{array}$ & Objeto & Significado & Ação \\
\hline Adaptador & $\begin{array}{l}\text { Adequar; ajustar; moldar } \\
\text { Foco na dimensão ambiente } \\
\text { Perfil adaptativo }\end{array}$ & $\begin{array}{l}\text { Rede social de } \\
\text { entretenimento Instagram; } \\
\text { alguns equipamentos de } \\
\text { ginástica (alteres, anilhas } \\
\text { etc.) }\end{array}$ & $\begin{array}{c}\text { Oferta de aulas e } \\
\text { consultorias on-line; aluguel } \\
\text { de equipamentos }\end{array}$ & $\begin{array}{l}\text { Utilização da rede social } \\
\text { Instagram para gravar e } \\
\text { postar aulas; aluguel de } \\
\text { equipamentos para os } \\
\text { consumidores assistir a aula } \\
\text { e fazer atividades físicas em } \\
\text { casa; oportunidade de novo } \\
\text { negócio }\end{array}$ \\
\hline Resiliente & $\begin{array}{l}\text { Firme; flexível } \\
\begin{array}{l}\text { Foco na dimensão } \\
\text { organização }\end{array} \\
\text { Perfil racional }\end{array}$ & $\begin{array}{l}\text { Rede social de } \\
\text { entretenimento Instagram; } \\
\text { alguns equipamentos de } \\
\text { ginástica (alteres, anilhas } \\
\text { etc.) }\end{array}$ & $\begin{array}{l}\text { Oferta de aulas on-line; } \\
\text { visita às residências dos } \\
\text { consumidores }\end{array}$ & $\begin{array}{l}\text { Utilização da rede social } \\
\text { Instagram para gravar e } \\
\text { postar aulas (desânimo no } \\
\text { início da pandemia, mas } \\
\text { para não prejudicar o } \\
\text { faturamento ofertaram aulas } \\
\text { on-line e visitas para poucos } \\
\text { consumidores) }\end{array}$ \\
\hline Desistente & $\begin{array}{c}\text { Abdicar; abandonar; cessar } \\
\text { Foco inadequado na } \\
\text { dimensão estratégia } \\
\text { Perfil pouco emergente }\end{array}$ & - & - & $\begin{array}{l}\text { Fechamento definitivo da } \\
\text { academia; aguardo pela } \\
\text { reabertura das academias } \\
\text { pelas autoridades locais }\end{array}$ \\
\hline Negador & $\begin{array}{l}\text { Teimar; insistir; rejeitar } \\
\text { Foco inadequado na } \\
\text { dimensão dirigente } \\
\text { Perfil pouco empreendedor }\end{array}$ & $\begin{array}{l}\text { Todos equipamentos de } \\
\text { ginástica }\end{array}$ & $\begin{array}{l}\text { Abertura das academias e } \\
\text { funcionamento normal }\end{array}$ & $\begin{array}{l}\text { Desconsideração dos } \\
\text { decretos e protocolos das } \\
\text { autoridades locais }\end{array}$ \\
\hline
\end{tabular}

Fonte: Elaborado pelos autores com base em Magaudda (2011), Terence (2008) e Terence, Escrivão Filho e Perussi Filho (2012) 
Figura 3 - Exemplos de empresários adaptadores, resilientes, desistes e negadores.

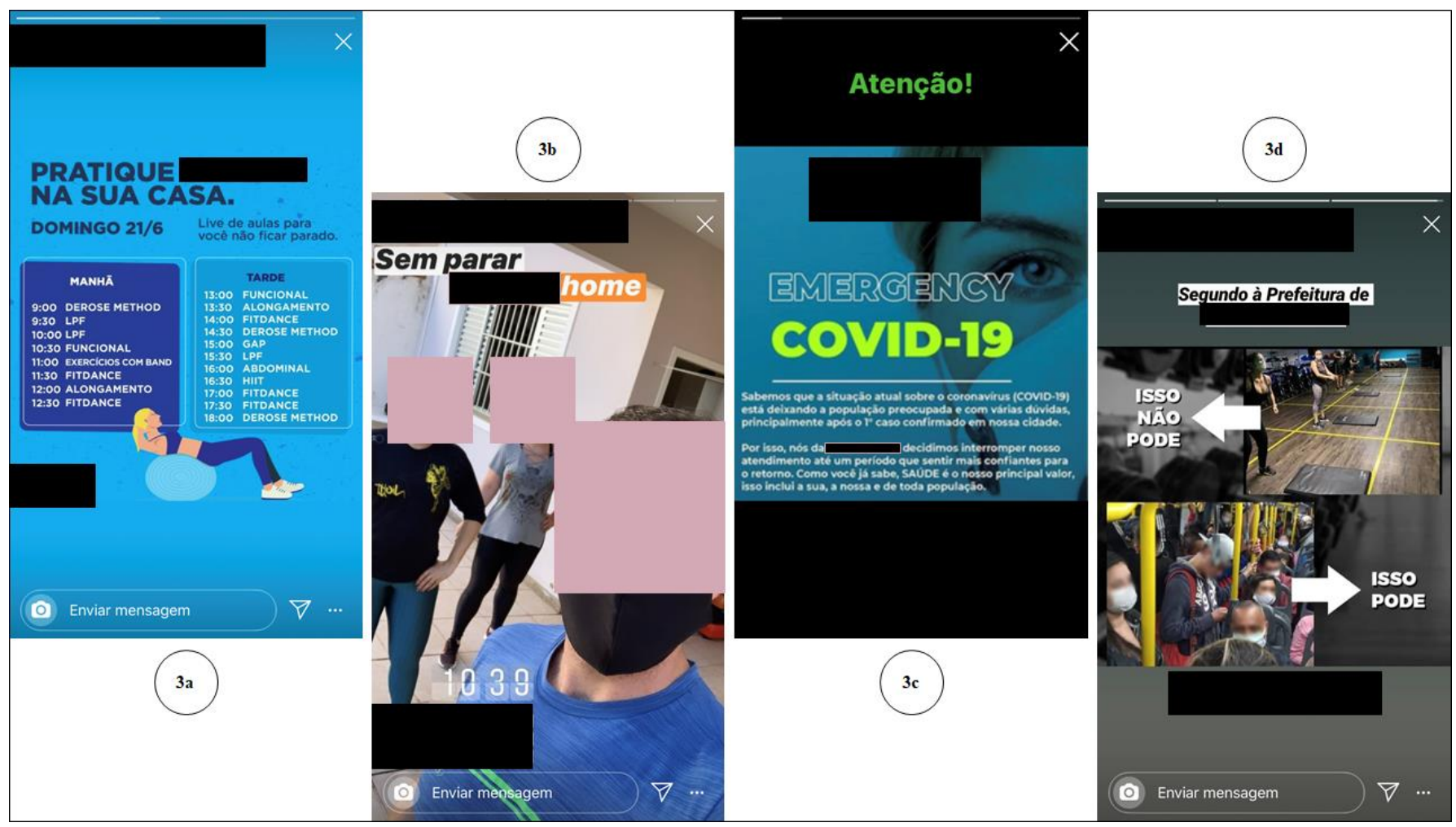

Fonte: Dados da pesquisa.

\subsection{Comportamento de consumidores de micro e pequenas academias de ginástica}

Os consumidores "adaptadores" adequaram, ajustaram e moldaram a forma de fazerem as atividades físicas (ver Figura 4a). Essas pessoas alugaram equipamentos de ginástica das próprias academias e, além deles, utilizaram o peso do próprio corpo e objetos domésticos para fazerem as atividades, como por exemplo, vassouras, cadeira, toalha, pacotes de arroz, embalagens de sabão líquido, mochila/sacola com livros, dentre outros. Outros compraram materiais como faixas elásticas de diferentes intensidades e níveis (baixo, médio, alto), cordas de pular, apoio/suporte para flexão, roda e aparelho de abdominal, alteres e anilhas de pequeno e médio porte etc. Além do mais, assistiram videoaulas postadas no perfil do Instagram das academias e tentaram reproduzir os movimentos. Compraram e/ou alugaram kits de ginásticas, kits de bikes e assinaram aplicativos da área. Provavelmente, não voltarão a frequentar uma academia física tão cedo.

Os "resilientes" são consumidores com perfis firmes e flexíveis (ver Figura 4b). Foram usuários que começaram a praticar atividades físicas em casa, pararam e voltaram depois de um tempo. Assim que o cenário da pandemia permitiu a abertura controlada das academias de ginástica, voltaram imediatamente às atividades presenciais.

Com um perfil menos animado, os consumidores "desistentes" abdicaram, abandonaram e cessaram todas as atividades físicas (ver Figura 4c). No início da pandemia, por intermédio das aulas postadas pelos empresários no Instagram, começaram a adaptar as atividades físicas para fazer em casa, mas com o passar do tempo desistiram e se afastaram das atividades.

Os consumidores "negadores" foram os mais resistentes (ver Figura 4d). Queriam voltar a praticar atividades físicas o mais rápido possível, não se adaptaram as atividades físicas em casa e pressionaram os poderes locais a abrirem as academias. Quando as atividades foram liberadas parcialmente pelas autoridades, não se preocuparam com as recomendações sanitárias e, em muitos casos, não utilizaram máscaras de proteção e álcool em gel 70\%, tampouco higienizaram os equipamentos. O Quadro 2 relaciona os tipos de consumidores e suas características com os objetos, significados e ações. 
Quadro 2 - Tipos de consumidores.

\begin{tabular}{|c|c|c|c|c|}
\hline Tipo & Característica & Objeto & Significado & Ação \\
\hline Adaptador & Adequar; ajustar; moldar & $\begin{array}{l}\text { Objetos domésticos } \\
\text { (vassoura, cadeira, toalha, } \\
\text { saco de arroz etc.); alguns } \\
\text { equipamentos de ginástica } \\
\text { (alteres, anilhas etc.) }\end{array}$ & $\begin{array}{l}\text { Compra de aulas e } \\
\text { consultorias on-line; aluguel } \\
\text { ou compra de equipamentos }\end{array}$ & $\begin{array}{l}\text { Utilização da rede social } \\
\text { Instagram para assistir } \\
\text { aulas; adaptação de objetos } \\
\text { domésticos para fazer } \\
\text { atividades físicas em casa; } \\
\text { aluguel de equipamentos da } \\
\text { academia que frequenta }\end{array}$ \\
\hline Resiliente & Firme; flexível & $\begin{array}{c}\text { Objetos domésticos } \\
\text { (vassoura, cadeira, toalha, } \\
\text { saco de arroz etc.) }\end{array}$ & $\begin{array}{c}\text { Compra de aulas e } \\
\text { consultorias on-line; } \\
\text { utilização de aplicativos } \\
\text { gratuitos }\end{array}$ & $\begin{array}{l}\text { Utilização da rede social } \\
\text { Instagram e aplicativos } \\
\text { gratuitos para assistir aulas; } \\
\text { adaptação de objetos } \\
\text { domésticos para fazer } \\
\text { atividades físicas em casa; } \\
\text { desistência por um tempo, } \\
\text { depois retornou as } \\
\text { atividades físicas em casa }\end{array}$ \\
\hline Desistente & Abdicar; abandonar; cessar & - & - & $\begin{array}{c}\text { Abandonou a prática de } \\
\text { atividades físicas; aguardo } \\
\text { pela reabertura das } \\
\text { academias pelas autoridades } \\
\text { locais }\end{array}$ \\
\hline Negador & Teimar; insistir; rejeitar & $\begin{array}{l}\text { Todos equipamentos de } \\
\text { ginástica }\end{array}$ & Frequência normal & $\begin{array}{c}\text { Desconsideração dos } \\
\text { decretos e protocolos das } \\
\text { autoridades locais; } \\
\text { frequência normal da } \\
\text { academia }\end{array}$ \\
\hline
\end{tabular}

Fonte: Elaborado pelos autores com base em Magaudda (2011)

Figura 4 - Exemplos de consumidores adaptadores, resilientes, desistes e negadores.

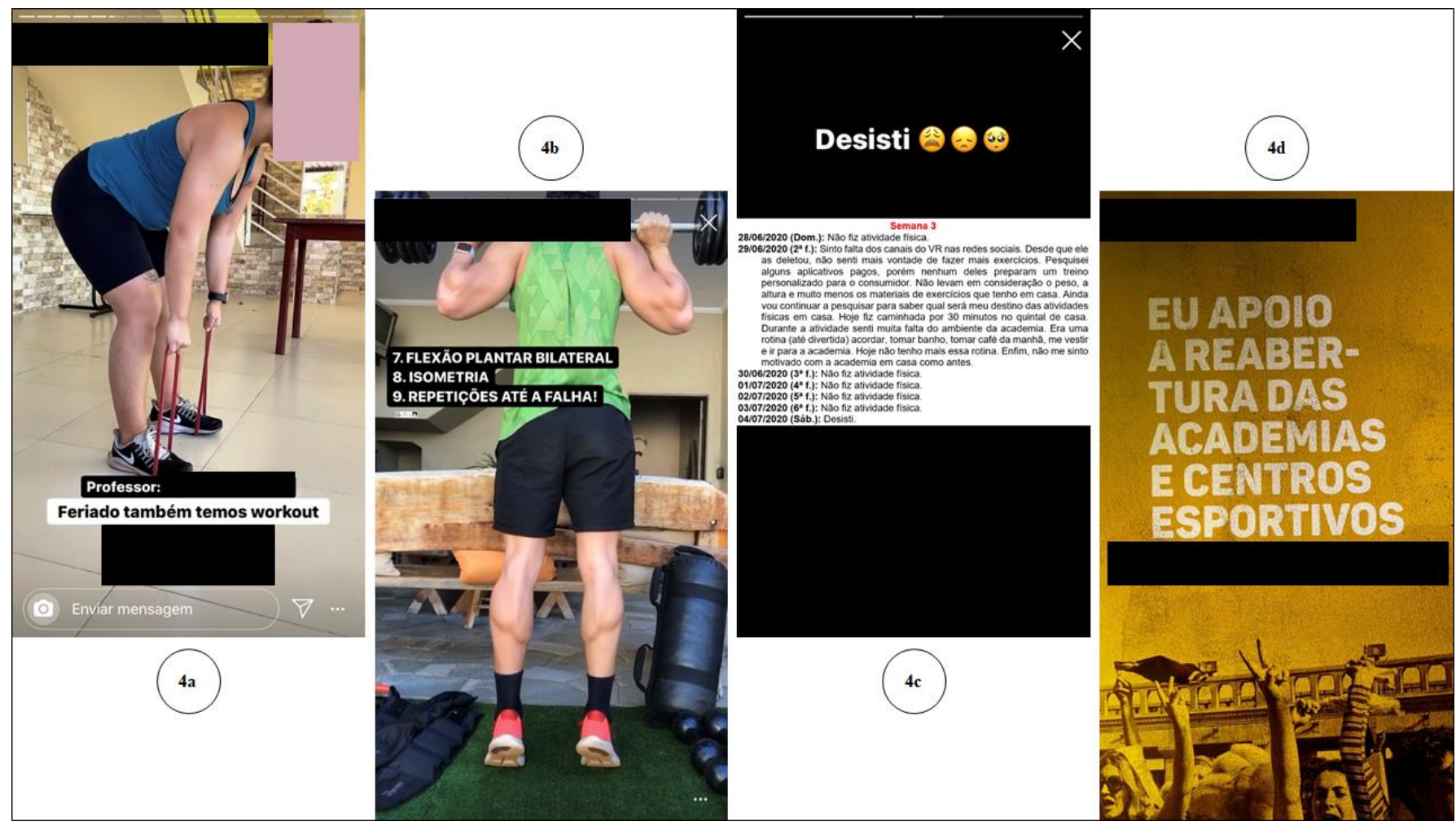

Fonte: Dados da pesquisa

Descrito os principais efeitos do trabalho, a seguir será relatada a análise dos resultados com o intuito de assimilar de forma ampla quais os tipos de comportamento de empresários e consumidores de micro e pequenas academias de ginástica na adaptação das práticas de atividades físicas em tempos de pandemia. 


\section{Discussão}

A pandemia de COVID-19 juntamente ao distanciamento social, isolamento e quarentena impuseram aos empresários e consumidores de micro e pequenas academias de ginástica medidas extremas, que afetaram de diversas formas os comportamentos perante os momentos de incertezas e ruptura de rotinas. Para o empresário, fechar as portas da MPE, mesmo que provisoriamente, produziu perdas no faturamento significativas. E para o consumidor, a ruptura de rotinas impôs ambiguidades no sentido de como manter as atividades físicas sem sair de casa. A análise de dados retornou quatro tipos de comportamentos de empresários e consumidores e suas estratégias para lidar com os momentos de incertezas: adaptador, resiliente, desistente e negador.

Para não prejudicar o faturamento das MPE's de academias, muito empresários e personal trainers ofertaram aulas em vídeos disponibilizadas na rede social Instagram (tipo adaptador, perfil adaptativo, foco no ambiente externo, Figura 5c) e/ou foram até as casas dos consumidores ensinar as atividades físicas (tipo resiliente, perfil racional, foco na organização, Figura 5b). Outros empresários desistiram, fecharam as portas e esperaram as autoridades locais liberarem a abertura dos estabelecimentos (tipo desistente, perfil pouco emergente, foco inadequado na estratégia, Figura 5d); ou negaram a realidade e rejeitaram os decretos para limitação e funcionamento das academias (tipo negador, perfil pouco empreendedor, foco inadequado no dirigente, Figura 5a).

Figura 5 - Empresários e a relação com as dimensões de especificidades de gestão de MPE.

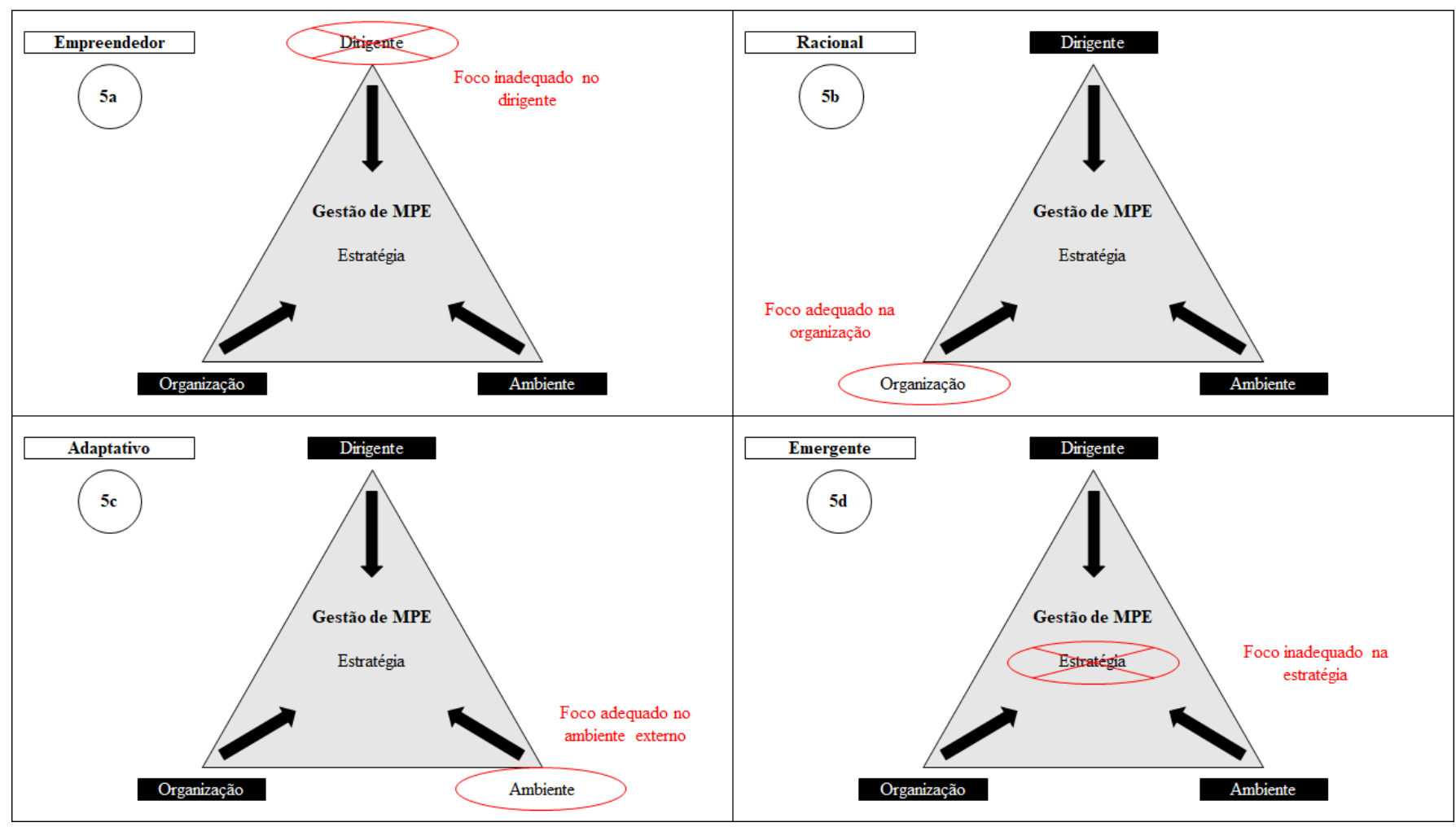

Fonte: Adaptado de Terence (2008) e Terence, Escrivão Filho e Perussi Filho (2012).

No lado dos consumidores, foi possível perceber a forma pela "qual", "como", "onde" e "se" o cliente adaptou e praticou as atividades físicas no instante da ruptura de rotinas. Alguns deles ajustaram as atividades físicas com os equipamentos que alugaram da academia ou que tinham em casa (perfil adaptador); e outros começaram a praticar os exercícios em casa, pararam, voltaram e na primeira oportunidade de reabertura do serviço, retornaram imediatamente às 
atividades presenciais (perfil resiliente). Muitos desistiram de praticar os exercícios físicos (perfil desistente); e houve até aqueles que voltaram na primeira oportunidade e ignoraram os protocolos sanitários (perfil negador).

Pode-se observar que a transição do físico para o tecnológico não foi tão simples. Na academia física, os equipamentos de ginástica já estão nos lugares adequados a cada tipo de exercício e os ventiladores e/ou ares-condicionados já estão ajustados. Para modificar as aulas para o virtual, as atividades instruídas nos vídeos e postagens foram realizadas com a ajuda do peso do corpo, alguns equipamentos que foram alugados pelos consumidores e objetos domésticos. Os empresários e consumidores, portanto, reestabeleceram a segurança das rotinas interrompidas por meio do alinhamento prático das atividades físicas, como em Phipps e Ozanne (2017).

Assim, a ruptura das rotinas fez com que não se tivesse mais os mesmos objetos, ou seja, não existe mais o espaço da academia nem os equipamentos de ginástica. Dessa maneira, os empresários e consumidores passaram a usar outros objetos e ao mudá-los, como em Magaudda (2011), modificam os significados. A academia de ginástica passou a funcionar não mais como um espaço social, mas ao fazer exercício em casa como saúde e manutenção do autocuidado, mudam as ações. Ou seja, os consumidores precisaram aprender a manusear algumas ferramentas do Instagram que antes eram desconhecidas ou pouco utilizadas, além de adaptar objetos, como por exemplo, vassouras, cadeiras e mochilas/sacolas com livros.

Na Figura 6, o circuito é composto dos elementos objeto, significado e ação e visa explicar a dinâmica da mudança e transformação das atividades práticas do ponto de vista dos consumidores. Esse esquema visa analisar os processos de mudanças nos padrões de consumo. As setas cinzas sólidas representam os relacionamentos constantes entre os três elementos que constituem as práticas como uma entidade completa, enquanto as setas pretas pontilhadas mostram os relacionamentos reais e influenciam esses elementos dinamicamente estabelecidos nas experiências dos consumidores perante a pandemia de COVID-19. O circuito explica, assim, o trabalho de reconfiguração das atividades físicas como realmente experimentada pelos consumidores, concentrando-se no nível do indivíduo no qual as suas práticas foram transformadas, isto é, ela dá sentido as experiências dos consumidores de academias de ginástica diante a ruptura de rotinas e os momentos de incertezas.

Figura 6 - Objeto, significado e ação perante Magaudda (2011).

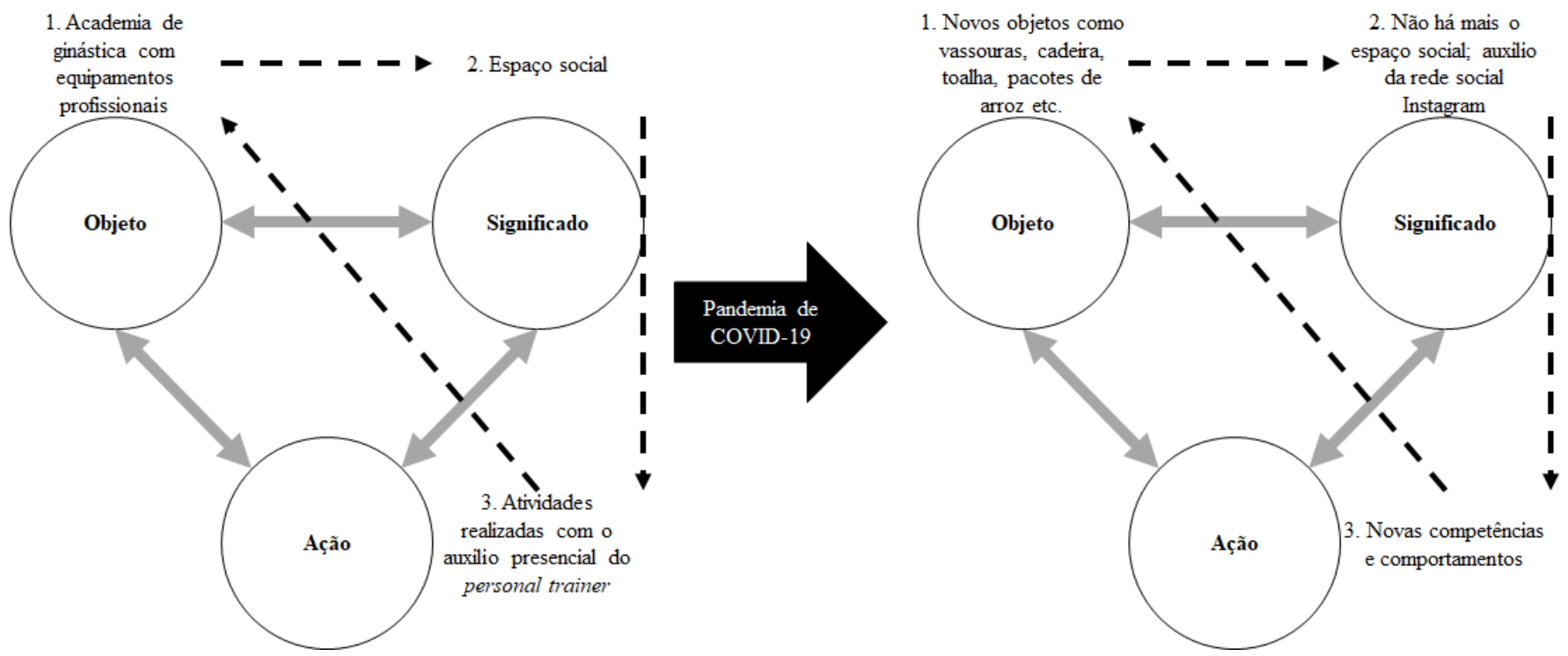

Fonte: Adaptado de Magaudda (2011).

Destaca-se que quando se faz a transição para o virtual, a conexão com a Internet pode apresentar falhas e/ou não funcionar, os computadores e/ou celulares podem ficar sem carga nas baterias, os fios dos carregadores e fones de ouvidos 
podem atrapalhar os movimentos nas atividades físicas e, caso o fone for sem fio pode, às vezes, não funcionar. São inúmeros contratempos que podem ocorrer e várias adaptações para se fazer.

Entretanto, os consumidores que não tiveram interrupção do serviço e receberam os treinos por meio da rede social consideram o serviço de forma positiva. Eles gostaram, se sentiram amparados e reconheceram a responsabilidade dos empresários e personal trainers das academias de ginástica. Para os que negaram, a prática ficou como estava, com os mesmos elementos.

Do ponto de vista dos empresários, quem vai oferecer um novo serviço ou adaptá-lo precisa ter o entendimento de quem vai usá-lo. Para os negadores, é preciso ter uma mudança de mentalidade, estar antenado aos momentos de incertezas, entender o que o consumidor quer hoje, o que quer para amanhã, pensar para quem vender, investir em pesquisa e testar ideias.

Por fim, é de registrar que durante este período, a pandemia possibilitou o mercado fitness criar novas empresas, mudar alguns nichos de mercado e conceber novos modelos de negócio, a saber: "Apoie uma Academia" (@apoieumaacademia no Instagram) para angariar fundos e auxiliar as academias em apuros financeiros; novos canais e perfis feitos por educadores físicos surgiram em outras redes sociais de entretenimento, como o Facebook, TikTok e YouTube, para o ensino do treino em casa, consultorias e vendas on-line de equipamentos de ginástica de pequeno porte; criação da academia móvel "Go Fit Truck" (@gofittruck no Instagram); consolidação de aplicativos e sites de treinos on-line como o "Darebee" (@darebeecom no Instagram), “Peloton” (@onepeloton no Instagram), "RadarFit” (@radarfit no Instagram) e “Treino Mestre” (@ treinomestre no Instagram); entre outros.

\section{Considerações Finais}

O objetivo desse artigo foi identificar quais os tipos de comportamento de empresários e consumidores de micro e pequenas academias de ginástica na adaptação das práticas de atividades físicas em tempos de pandemia. Pode-se considerar que o propósito foi atingido, uma vez que a pesquisa resultou em quatro tipos de comportamentos de empresários e consumidores: adaptador, resiliente, desistente e negador.

A metodologia utilizada foi satisfatória para atingir as análises necessárias e a literatura averiguada para embasar o estudo atendeu as expectativas. Por meio do estudo baseado na netnografia, pôde-se perceber que os comportamentos de empresários e consumidores frente aos desafios na ruptura de rotinas em momentos de incertezas variam de acordo com a cultura de consumo na qual estão inseridos. Alguns reagiram positivamente, como os adaptadores e resilientes; outros se perderam no desafio ou no senso de coletividade, como os desistentes e negadores.

Por se tratar de um fenômeno ainda recente, destaca-se a escassez de publicações que tratam especificamente da relação das empresas de pequeno porte com seus consumidores em ruptura de rotinas e momentos de incertezas, como o da pandemia de COVID-19. A pesquisa tem a importância histórica no momento em que vive a humanidade para entender o comportamento de empresas e consumidores de MPE's de academias de ginásticas em tempos de pandemia. Por isso, é importante ressaltar dois pontos: um é o entendimento da criação de estratégias por parte dos gestores/proprietários das academias, que devem levar em consideração que a gestão de MPE's requer uma visão sistêmica e compreensão das especificidades do lugar onde está inserida, como estudado em Terence (2008) e Terence et al. (2012) e, mais recentemente, em Almeida et al. (2021).

O outro ponto é o entendimento do consumo quando as pessoas têm sua rotina interrompida (Phipps \& Ozanne, 2017) $\mathrm{e}$, neste caso, radicalmente alterada. Este momento se torna relevante tanto pelo entendimento de um mercado em um instante de alteração nas atividades do cotidiano quanto pelo entendimento do consumidor em relação a situação atípica para lidar. Tal pesquisa tem potencial para gerar contribuição acadêmica e para políticas públicas em relação ao consumo em momentos de incertezas e ruptura de rotinas, como também características de mudança de mercado específicas para MPE’s. 
Trabalhos futuros poderão ser desenvolvidos acerca do entendimento de como os consumidores reagiram ao longo do tempo, como o comportamento foi mudando ao longo da pandemia, como está na atualidade e como tal comportamento interferiu na forma como os empresários criaram, adaptaram e organizaram as atividades no cotidiano das MPE's. A pesquisa também poderá aprofundar em cada um dos atores: empresários e consumidores.

\section{Agradecimentos}

Os autores agradecem à Universidade Federal de Ouro Preto (UFOP), à Pró-reitoria de Pesquisa, Pós-Graduação e Inovação (PROPPI/UFOP), à Fundação de Amparo à Pesquisa do Estado de Minas Gerais (FAPEMIG) e à Coordenação de Aperfeiçoamento de Pessoal de Nível Superior (CAPES) pelo apoio na realização desta pesquisa.

\section{Referências}

Alecrim, J. V. C. (2020). Políticas públicas de esporte e lazer na promoção da saúde e COVID-19: o que devemos aprender para o futuro. Boletim de Conjuntura, 2(5), 97-100. https://doi.org/10.5281/zenodo.3774408\%20

Almeida, T. E. (2019). Gestão de micro e pequenas empresas: uma proposta pedagógica para o desenvolvimento de uma disciplina do curso de Engenharia de Produção. Revista Gestão da Produção, Operações e Sistemas (GEPROS), 14(3), 110-121. https://doi.org/10.15675/gepros.v14i3.2609

Almeida, T. E. (2020). Desafios na gestão logística de uma microempresa fabricante de biscoitos na perspectiva da integração das atividades primárias e de apoio. Research, Society and Development (RSD), 9(8), e722986023. https://doi.org/10.33448/rsd-v9i8.6023

Almeida, T. E., Morais, I. C., \& Reis, L. P. (2021). Gestão de micro e pequenas empresas na engenharia de produção: revisão sistemática de literatura. Research, Society and Development (RSD), 10(13), e409101321274. https://doi.org/10.33448/rsd-v10i13.21274

Aquino, E. M. L., Silveira, I. H., Pescarini, J. M., Aquino, R., Souza-Filho, J. A. D., Rocha, A. S., \& Lima, R. T. R. S. (2020). Social distancing measures to control the COVID-19 pandemic: potential impacts and challenges in Brazil. Ciência \& Saúde Coletiva, 25(Supl. 1), 2423-2446. https://doi.org/10.1590/141381232020256.1 .10502020

Araújo Júnior, J. A., Mendonça, G., \& Toscano, J. J. O. (2020). Atuação das academias de ginástica durante a pandemia da COVID-19. Scientia Plena, 16(10), 102801. https://doi.org/10.14808/sci.plena.2020.102801

Belk, R., Fischer, E., \& Kozinets, R. V. (2013). Qualitative consumer \& marketing research. Sage Publishing.

Bezerra, A. C. V., Silva, C. E. M., Soares, F. R. G., \& Silva, J. A. M. (2020). Factors associated with people's behavior in social isolation during the COVID19 pandemic. Ciência \& Saúde Coletiva, 25(Supl. 1), 2411-2421. https://doi.org/10.1590/1413-81232020256.1.10792020

Bisneto, C. D., \& Simão, J. F. (2020). Responsabilidade civil do estado pelas restrições impostas em razão da pandemia do coronavírus. Revista Jurídica LusoBrasileira, 6(4), 725-753. https://www.cidp.pt/revistas/rjlb/2020/4/2020_04_0725_0753.pdf

Bodlaj, M., \& Cater, B. (2019). The impact of environmental turbulence on the perceived importance of innovation and innovativeness in SME's. Journal of Small Business Management, 57(Supl. 2), 417-435. https://doi.org/10.1111/jsbm.12482

Brasil (2022). Ministério da Saúde. Coronavírus. https://www.gov.br/saude/pt-br/coronavirus

Camilo, J. A. O., Roth, A. P., Raucci, G. Z., \& Rubio, K. (2020). Entre o cuidado e o mercado: os sentidos da Covid-19 para professores de lutas. Revista Brasileira de Psicologia do Esporte, 10(1), 15-32. https://doi.org/10.31501/rbpe.v10i1.11727

Carvalho, F. F. B., Silva, R.G., \& Oliveira, R. B. (2020). A essencialidade das academias de ginástica para a saúde diante da pandemia da COVID-19 no Brasil. Revista Brasileira de Atividade Física \& Saúde, 25, e0116. https://doi.org/10.12820/rbafs.25e0116

CONFEF (2020). Conselho Federal de Educação Física. Pesquisa de Pessoas Jurídicas Registradas. https://www.confef.org.br/confef/pj-registradas

Feter, N., Caputo, E. L., Doring, I. R., Leite, J. S., Cassuriaga, J., Reichert, F. F., \& Rombaldi, A. J. (2021). Sharp increase in depression and anxiety among Brazilian adults during the COVID-19 pandemic: findings from the PAMPA cohort. Public Health, 190, 101-107. https://doi.org/10.1016/j.puhe.2020.11.013

Golder, P. N. (2000). Historical method in marketing research with new evidence on long-term market share stability. Journal of Marketing Research, 37(2), 156-172. https://doi.org/10.1509/jmkr.37.2.156.18732

Guimarães, J. A. C., Guerra, P. H., Ueno, D. T., Christofoletti, A. E. M., \& Nakamura, P. M. (2020). Estudo transversal sobre uso de ferramentas virtuais para orientar a atividade física durante a COVID-19. Revista Brasileira de Atividade Física \& Saúde, 25, e0150. https://doi.org/10.12820/rbafs.25e0150

IHRSA (2020). International Health, Racquet \& Sportsclub Association. The 2020 IHRSA Global Report: the state of the health club industry. Boston: IHRSA.

Jankowska, J. (2021). Fitness culture in the era of COVID-19: new reality, new challenges. Perspective of personal trainers. Journal of Physical Education and Sport, 21(Supl. 2), 1225-1233. https://doi.org/10.7752/jpes.2021.s2156 
Kozinets, R. V. (2020). Netnography: the essential guide to qualitative social media research. (3a ed.). Sage Publishing.

Lang, B., Dolan, R., Kemper, J., \& Northey, G. (2021). Prosumers in times of crisis: definition, archetypes and implications. Journal of Service Management, 32(2), 176-189. https://doi.org/10.1108/JOSM-05-2020-0155

Lima, J. F., \& Silva, G. (2019). Desafios para inovar na micro e pequena empresa. Revista da Micro e Pequena Empresa (RMPE), $13(2)$, 85-97. https://doi.org/10.6034/rmpe.v13i2.1322

Magaudda, P. (2011). When materiality 'bites back': digital music consumption practices in the age of dematerialization. Journal of Consumer Culture, 11(1), 15-36. https://doi.org/10.1177/1469540510390499

Martins, J. G. F., Leone, R. J. G., \& Leone, N. M. C. P. G. (2017). Proposta de método para classificação do porte das empresas. Revista Connexio, 6(1), 139155. Retrieved from https://repositorio.unp.br/index.php/connexio/article/view/1679

Murphy, C., Naert, S., \& Strong, C. (2020). Coronavirus and behavior change: what does this mean for brands? IPSOS, 2020.

Oliveira, A. K. B., Araújo, M. S., Alves, S. F. L., Rocha, L. B., Silva, M. L., Rocha, R. S. B., \& Cunha, K. C. (2020). Quality of life and social distancing: systematic review of literature. Research, Society and Development (RSD), 9(8), e318985885. https://doi.org/10.33448/rsd-v9i8.5885

Phipps, M., \& Ozanne, J. L. (2017). Routines disrupted: reestablishing security through practice alignment. Journal of Consumer Research, 44(2), 361-380. https://doi.org/10.1093/jcr/ucx040

Raiol, R. A. (2020). Praticar exercícios físicos é fundamental para a saúde física e mental durante a Pandemia da COVID-19. Brazilian Journal of Health Review, 3(2), 2804-2813. https://doi.org/10.34119/bjhrv3n2-124

Rodrigues, A. C. A., Moscon, D. C. B., Queiroz, G. C., \& Silva, J. C. (2020). Trabalhadores na pandemia: múltiplas realidades, múltiplos vínculos, 2. In: Moraes, M. M. (Ed.). Os impactos da pandemia para o trabalhador e suas relações com o trabalho (pp. 1-14). Artmed.

Rodríguez-Cañamero, S., Gallardo, L., Felipe, J. L., \& García-Unanue, J. (2018). Economic trend analysis of the fitness sector. Journal of Physical Education and Sport, 18(2), 575-584. https://doi.org/10.7752/jpes.2018.01010

Rose, G. (2016). Visual methodologies: an introduction to researching with visual materials. (4a ed.). Sage Publishing.

Sá, C. D. S. C. D., Pombo, A., Luz, C., Rodrigues, L. P., \& Cordovil, R. (2021). COVID-19 social isolation in Brazil: effects on the physical activity routine of families with children. Revista Paulista de Pediatria, 39, e2020159. https://doi.org/10.1590/1984-0462/2021/39/2020159

SEBRAE \& DIEESE (2020). Serviço Nacional de Apoio às Micro e Pequenas Empresas \& Departamento Intersindical de Estatística e Estudos Socioeconômicos. Anuário do trabalho nos pequenos negócios: 2018. (11a ed.). DIEESE.

SEBRAE (2020). Serviço Nacional de Apoio às Micro e Pequenas Empresas. Impactos e tendências da COVID-19 nos pequenos negócios. (4a ed.). SEBRAE.

Shove, E. (2003). Converging conventions of comfort, cleanliness and convenience. Journal of Consumer Policy, 26(4), 395-418. https://doi.org/10.1023/A:1026362829781

Terence, A. C. F. (2008). Processo de criação de estratégias em pequenas empresas: elaboração de um mapa estratégico para empresas de base tecnológica do polo de São Carlos/SP (Tese de doutorado). Escola de Engenharia de São Carlos, Universidade de São Paulo, São Carlos, SP.

Terence, A. C. F., Escrivão Filho, E., \& Perussi Filho, S. (2012). Os modos de formação de estratégias e os elementos do sistema de administração estratégica: liderança, ambiente e organização. In Anais XLVII Asamblea Anual del Consejo Latinoamericano de Escuelas de Administración. CLADEA. 